THURSDAY, DECEMBER 30, I869

\section{A DEDUCTION FROM DARWIN'S THEORY}

THERE is one important consequence deducible from

Darwin's profound theory which has not yet been noticed so far as I am aware. The theory is capable under certain reasonable conditions of accounting for the fact that the highest forms of civilisation have appeared in temperate climates.

Although some apparent exceptions might be adduced, it is no doubt true that man displays his utmost vigour and perfection, both of mind and body, in the regions intermediate between extreme heat and extreme cold, allowance being made for the reduced temperature of elevated mountain districts. The explanations hitherto given of this fact are of a purely hypothetical and shallow character. It is said, for instance, that the prolific character of the tropical climate too easily furnishes man with subsistence, so that his powers are never properly called into action. On the other hand in the Arctic regions nature is too sterile and no exertions can lead to the accumulation of much wealth. This explanation obviously involves the gratuitous hypothesis that man has been created with powers exactly suited to be called forth by just that degree of difficulty experienced in a temperate climate. There are those even who maintain our peculiar British climate to be the very best possible, because it taxes our powers of endurance to the last point which they can bear, and thus calls forth the greatest amount of energy. But here again is the assumption that the British people and the British climate were specially created to suit each other.

The theory of natural selection, on the other hand, represents that great method by which infinitely numerous adaptations will always be produced throughout time. Whatever happens in this material world must happen in consequence of the properties originally impressed upon matter, and our notions of the wisclom embodied in the Creation must be infinitely raised when we understand, however imperfectly, its true method. The continual resort to special inventions and adaptations must surely be below the greatness of a Power which could so design and create matter from the first that it must go on thenceforth inventing and adapting forms of life without apparent limit, in pursuance of one uniform principle.

I conceive it to be the essential consequence of Darwin's views that no form of life is to be regarded as a fixed form; but that all living beings, inciuding man, are in a continual process of adjustment to the conditions in which they live. If this be so, it will of necessity follow that the longer any race dwells in given circumstances, the more perfectly will it become adapted to those circumstances. A migratory race, on the contrary, will always be liable to enter climates unsuited to it, and less favourable to the development of the greatest amount of energy. Negroes can bear a tropical heat simply because the race has grown more accustomed to it than Europeans, who bring with them indeed a superior degree of energy and intellect, but soon sicken and fail to reproduce themselves in equal perfection.

The intellect of man renders him far more migratory than most other animals, and when we look over long periods of time we must regard him as in a constant state of oscillation between the equator and the borders of perpetual snow. It will of necessity follow that the race, as a whole, will be better adapted to a medium than to an extreme climate. Not only may the same race have passed alternately through colder and hotter climates, but it is obvious that the tribes which intermix and intermarry in temperate regions will have come, some from a hotter and some from a colder region. The amalgamated race will therefore be precisely adapted to a medium climate. The inhabitants of the Arctic regions, on the contrary, must have come entirely from a warmer climate, and those of a tropical region from a colder climate, so that ages must pass before either re-adapts itself perfectly to its new circumstances.

It is hardly to be expected that history can afford complete corroboration of this theory; but $I$ do not think that historical facts can be adduced in serious opposition to it. The progress of archæological and linguistic inquiry shows more and more clearly that the civilised parts of the earth have been inhabited by a succession of different races. A really aboriginal and indigenous people, growing upon a single isiland or spot of ground without kinship with other races, is not known to exist ; and it is almost certain that all races have descended from a few stocks, if not from a single one. The evidences of extensive and frequent migrations are thus most complete, even if we had not distinct historical facts concerning the rapid and extensive movements of the Goths, Huns, Moors, Scandinavians, and many other races.

If the historical evidence disagrees with the theory in any point, it is that the migrations from temperate to extreme climates greatly over-balance any opposite movement. It would hardly, perhaps, be too much to represent the temperate regions of the Old World as the birthplace of successive races, which have diverged and died away more or less rapidly in distant and extreme climates. But if such be the conclusion from historical periods, it would only indicate that the human race had already acquired, in prehistoric times, a constitution displaying its greatest vitality in temperate regions. There can be no doubt that, were the rest of the world uninhabited by man, a very inferior race, such as the negroes of tropical Africa, would gradually re-people it ; but they cannot do so in the present state of things, because they come into conflict with races of superior intellect and energy.

I would add in conclusion that the utmost result of speculations of this kind, supposing them to be valid, would consist in establishing a general tendency, so that the probabilities will be in favour of a great display of civilisation occurring in temperate climates rather than elsewhere. I do not for a moment suppose that any common physical cause, such as soil, climate, mineral wealth, or geographical position, or any combination of such causes, can alone account for the rise and growth of civilisation in Assyria, Egypt, Greece, Italy, or England. Material resources are nothing without the mind which knows how to use them. No physiology of protoplasm, no science that yet has a name, or perhaps ever will have a name, can account for the evolution of intellect in all its endless developments. The vanity of the Comtists leads them to suppose that their philosophy can compass 
the bounds of existence and account for the evolution of history; but the scientific man remembers that however complicated the facts which he reduces under the grasp of his laws, yet beyond all doubt there remain other groups of facts of surpassing complication. Science may ever advance, but, like an improved telescope in the hands of an astronomer, it only discloses the unsuspected extent and difficulty of the phenomena yet unreduced to law.

W. Stanley Jevons

\section{THE STATE TELEGRAPHS}

UR Government-always the last among European Governments to endow the nation with any benefit resulting from the advance of science-has at length awakened to the fact that the electric current is the scientific modern equivalent for the ancient post-boy, and we are to have a State Telegraph as we have a State Postal system.

As early as $1854, \mathrm{Mr}$. Thomas Allan, the electrician, published a paper entitled "Reasons for the Government Annexing an Electric Telegraph System to the General Post Office," in which he recommended the adoption of a shilling rate, for messages of twenty words, throughout the United Kingdom. This paper was published a second time in 1863 . In $1856, \mathrm{Mr}$. Baines, an officer in the General Post Office, submitted to the Lords of the Treasury a plan for the annexation of the telegraphs, and a general charge of sixpence for messages of twenty words. In I86I, a memorandum by Mr. Ricardo, chairman of the Electric and International Telegraph Company, recommending the transfer of the telegraphs to the Government, was forwarded to the Chancellor of the Exchequer. Late in the year 1865 the proposition was again brought forward in the report of a committee appointed by the Edinburgh Chamber of Commerce "to consider the present condition of telegraphic communication in the United Kingdom, with a view to its improvement." In June I866, Mr. Edwin Chadwick also forwarded a like scheme to the Chancellor of the Exchequer. The substance of all these papers was to the effect that the existing charges were too high, that the rapidity of transmission of messages was bad, that improvements are slow where they have to be made by competing companies fighting for high dividends, and that telegraphing in consequence was in a more backward state in the United Kingdom than in Switzerland and Belgium.

In September $1865, \mathrm{Mr}$. Scudamore was requested by the Postmaster-General to take the whole subject into consideration, and to report thereon. His first report was presented in July 1866 , followed by a second in February 1868. These reports set forth that before December 1862 messages of twenty words were transmitted for fifteen pence to or from any part of Belgium, in which country the telegraphs are under the control of the State. At the end of 1862 the charge was reduced to tenpence, and in December 1865 the charge was still further reduced to fivepence. The hours of business in the telegraphic offices in Belgium are much the same as those adopted in England. The clerks have the power, which they use largely, of altering the wording of messages so as to make them read clearer, and to prevent mistakes-a plan which manifestly would not work in
England, and which would lead to many legal and other difficulties. The result of the reductions in charges was, that in 1860 one telegram was transmitted in Belgium to every 218 letters passing through the post; in 1863 , one message was transmitted to every II4 letters; and in I866, the proportion was one telegram to every 37 letters. He also reported that the charge for the transmission of messages of twenty words between any two towns in Switzerland was tenpence. In 1860 , one telegram was transmitted in Switzerland to every 84 letters; in 1863 , one telegram to every 74 letters ; and in 1866 , one telegram to every 69 letters. In the United Kingdom the proportion of telegrams to letters was, in 1860 , one to 296 ; in 1863 , one to 197 ; and in 1866 , one to 121 . At the close of the year, the telegraphic systems of Belgium and Switzerland had been in operation about fifteen years, and the working expenses during that period had amounted in the case of Switzerland to about 68 per cent., and Belgium $62 \frac{1}{2}$ per cent. of the total revenue during the period. At the end of the year I 866, both Governments had a good surplus on hand from the telegraphic departments. The post offices of Switzerland and Belgium have less work than that of the United Kingdom, as shown by the following table, giving national statistics for the year 1865 :-

\begin{tabular}{|c|c|c|}
\hline Nation. & $\begin{array}{c}\text { Number of Inland } \\
\text { Telegrams. }\end{array}$ & $\begin{array}{c}\text { Number of Inland } \\
\text { Letters. }\end{array}$ \\
\hline Belgium , : & $\begin{array}{c}332,718 \\
364,118 \\
\text { Switzerland } \\
\text { United Kingdiom }\end{array}$ & $\begin{array}{c}24,530,688 \\
25,183,156 \\
706,057,667\end{array}$ \\
\hline
\end{tabular}

From these figures, Mr. Scudamore concluded that the use of the telegraphs was in a more backward state in the United. Kingdom than in Switzerland or Belgium; and he recommended their transference to the Government. One principal reason urged by him to prove that the Government could better afford to send messages at a lower rate than the companies was, that the post offices could spare for the use of the telegraph 12,000 offices rent-free, and a large staff of officials at present engaged, but not all of them fully employed throughout the whole of their hours of duty.

He therefore recommended the purchase of the telegxaphs by the State. In August last an Act of Parliament was passed by the late Government sanctioning the plan, and authority was given to buy up the telegraphs by paying the companies $£ 5,715,0488$ s. I $d$. (The odd elevenpence shows the extreme nicety of the calculation.) The Electric International Telegraph Company will receive $£ 2,938,82695$. od.; the British and Irish Magnetic, EI,243,536; Reuter's Telegram Company, Limited, $£ 726,000$; the Universal Private Telegraph Company, $£ 184,421$ 10s.; the London and Provincial Telegraph Company, Limited, $£ 60,000$; and the United Kingdom Telegraph Company, Limited, $£ 562,2649$ s. I $\mathrm{I} d$. At the present time everything relating to the transfer of the telegraphs to the Government is in a transition state, very many of the arrangements not having as yet been completed. It is intended, if possible, to effect the transfer on the Ist of January next; but so much preliminary work remains to be done, that it is doubtful whether all will be ready by that date. A large room has 